\title{
Extracts of endophytic fungus xkc-s03 from Prunella vulgaris L. spica inhibit gastric cancer in vitro and in vivo
}

\author{
JIANAN TAN, HAIZHI QI and JIANGDON NI
}

\author{
Department of Surgery, Second Hospital of Zhongnan University, Changsha, Hunan 410011, P.R. China
}

Received March 10, 2014; Accepted September 26, 2014

DOI: $10.3892 / 01.2014 .2722$

\begin{abstract}
Prunella vulgaris L. belongs to the Prunella genus and has been proven effective in the treatment of gastric cancer, however, the therapeutic activity of the endophytic fungi is not yet well understood. The results of the present study suggest that the ethyl acetate extract (S03-EA) of the endophytic fungus XKC-S03, isolated from Prunella vulgaris L. spica, is a potent anticancer agent with the potential to treat gastric cancer. In the present study, the effects of S03-EA on gastric cancer in vitro and in vivo were determined using the 1-(4,5-dimethylthiazol-2-yl)-3,5-diphenylformazan assay and the human gastric cancer SGC 7901 cell xenograft model. The tumor tissue was fixed with $10 \%$ formaldehyde solution and the levels of the apoptotic proteins, B-cell lymphoma protein-2 (Bcl-2), Bcl-2-associated X protein (Bax) and pro-angiogenic vascular endothelial growth factor (VEGF), were measured by immunohistochemistry. The results indicated that treating SGC 7901 cells with petroleum ether (S03-PE), ethyl acetate (S03-EA) or dichloromethane (S03-DM) extracts from the $\mathrm{XKC}-\mathrm{S} 03$ fermentation broth inhibited cell proliferation. S03-EA demonstrated the best activity, with a half maximal inhibitory concentration of $25.89 \mu \mathrm{g} / \mathrm{ml}$ and dose-dependent suppression of the SGC 7901 tumor cells in vivo, without any evident adverse effects. In addition, the $100-\mathrm{mg} / \mathrm{kg} / \mathrm{day}$ S03-EA-treated tumor tissue revealed a downregulation of Bcl-2 and VEGF expression and an upregulation of Bax expression. In conclusion, the S03-EA extract of XKC-S03, isolated from Prunella vulgaris L. spica, exhibits a growth-suppressive activity on gastric cancer in vitro and in vivo.
\end{abstract}

\section{Introduction}

The increase in the incidence of cancer has become a worldwide health concern, with gastric cancer accounting for a large proportion of cancer-related mortalities. A global annual

Correspondence to: Dr Jianan Tan, Department of Surgery, Second Hospital of Zhongnan University, Building 2, 403 Renmin Road, Jiarun, Changsha, Hunan 410011, P.R. China

E-mail: tanjianandr@yeah.net

Key words: gastric cancer, Prunella vulgaris L., endophytic fungi, ethyl acetate extract case-fatality ratio (CFR) of 0.75 exists for gastric cancer, with $\sim 934,000$ new cases diagnosed and 700,349 associated fatalities. The CFR of gastric cancer exceeds that of colon (CFR, 0.52), breast (CFR, 0.36) and prostate (CFR, 0.33) cancer $(1,2)$. In 2006, gastric cancer was the fifth most common newly diagnosed cancer and the fourth most common cause of mortality in Europe (3). The majority of gastric cancer patients are diagnosed with locally advanced or metastatic disease. Furthermore, gastric cancer commonly has a poor prognosis, particularly if it localized to the cardia and gastroesophageal junction. It is estimated that $40-60 \%$ of patients undergoing treatment for tumor resection, develop recurrence (4). Despite this, using chemotherapy to treat other non-hematological cancers, such as breast and colorectal cancer, has taken priority over gastric cancer in recent decades. Therefore, a requirement exists for renewable, environmentally friendly and accessible therapeutic agents to treat gastric cancer (5).

Prunella vulgaris L. belongs to the Prunella genus (Lamiaceae) and has been used worldwide for centuries as an alternative medicine in the treatment of fungal and bacterial infections. In addition, anti-oxidant (6,7), anti-allergy (8), immunomodulatory (9), anti-diabetic (10) and anticancer (including lymphoma (11), breast cancer (12) and esophageal cancer) (13) activities have been observed in recent years. As previously reported, the injection of Prunella vulgaris L. induces a significant effect on the human gastric cancer SGC 7901 cell line (14), however, few studies have been performed on the endophytic fungi XKC-S03, extracted from the Prunella vulgaris L. plant. In addition, compared with their counterparts derived from conventional medicinal plants, the use of active metabolites from endophytic fungi has a number of advantages. These include minimal destruction of resources, sustainable utilization, straightforward large-scale industrial production and simple quality control. At present, an increasing number of compounds with various bioactivities are being isolated from endophytic fungi (15-18). Therefore, the objective of the present study was to investigate the therapeutic potential of the endophytic fungi from Prunella vulgaris L. in vivo and in vitro, and to examine the molecular targets for treating gastric cancer.

\section{Materials and methods}

Samples. During summer 2009, the endophytic fungus $\mathrm{XKC}-\mathrm{S} 03$ was isolated from the spicae of Prunella vulgaris L., which were collected from the Second Hospital of 
Zhongnan University, Changsha, China. In total, 10 liters of $\mathrm{XKC}-\mathrm{S} 03$ fermentation broth was isolated using 30 liters of petroleum ether (S03-PE), ethyl acetate (S03-EA), dichloromethane (S03-DM) and n-butyl alcohol (S03-BA) (all obtained from Santa Cruz Biotechnology, Inc., Santa Cruz, CA, USA), to obtain 3.9-, 10.3-, 3.0- and 7.2-g extracts, respectively.

Reagents. The 3-(4,5-dimethylthiazol-2-yl)-2,5-diphenyltetrazolium bromide (MTT) assay was purchased from Amresco (Solon, OH, USA). Polyclonal rabbit anti-human vascular endothelial growth factor (VEGF; dilution 1:2,000; catalogue number, ab9571), polyclonal mouse anti-human B-cell lymphoma protein-2 (Bcl-2; dilution, 1:3,000; catalogue number, ab117115) and polyclonal rabbit anti-human Bcl-2-associated X protein (Bax; dilution, 1:2,000; catalogue number, ab7977) antibodies were purchased from Abcam (Cambridge, UK). Cyclophosphamide (CTX) was purchased from the National Institutes for Food and Drug Control, (Beijing, China).

Cell lines and culture. The SGC-7901 cell line was purchased from the Beijing Institute for Cancer Research (Beijing, China) and maintained in RMPI 1640 medium (Beijing Solarbio Science and Technology Co., Ltd., Beijing, China), which contained $100 \mathrm{U} / \mathrm{ml}$ penicillin and $100 \mathrm{mg} / \mathrm{ml}$ streptomycin. The medium was supplemented with $15 \%$ fetal bovine serum (Zhejiang Tianhang Biological Technology Co., Ltd., Hangzhou, China) and cultures were incubated at $37^{\circ} \mathrm{C}$ in a humidified atmosphere of $5 \% \mathrm{CO}_{2}$.

Cell proliferation assay. Cell proliferation was analyzed using the MTT assay as previously described (19). After 12h, the SGC 7901 cells $\left(1 \times 10^{5}\right)$ were seeded into a 96-well plate and equal volumes of different concentrations of XKC-S03 extracts $(25,50,100,250$ and $500 \mu \mathrm{g} / \mathrm{ml})$ were added to the cells for 24, 48 and $72 \mathrm{~h}$. Following this, MTT (final concentration, $5 \mathrm{mg} / \mathrm{ml}$ ) was added and incubated at $37^{\circ} \mathrm{C}$ for $4 \mathrm{~h}$. The medium was removed, formazan was dissolved in dimethylsulfoxide and the optical density was measured at $570 \mathrm{~nm}$ using an ELISA plate reader (MQX200; BioTek Co., Ltd, Winooski, CA, USA). All the experiments were performed in triplicate, and three independent experiments were conducted. The rate of cell viability to control (I\%) was calculated as: $\mathrm{I} \%=\mathrm{A} 570$ (treated) $/ \mathrm{A} 570$ (control) $\mathrm{x} 100$ (20). CTX and phosphate-buffered saline were used as positive and negative controls, respectively.

Antitumor activity of SO3-EA in vivo. In total, 40 male nude BALB/c mice, aged 6-8 weeks old and weighing between 20 and 22 g, were obtained from the Animal Research Center, Capital Medical University (Beijing, China). The SGC-7901 cells $\left(5 \times 10^{6}\right.$ in $0.5 \mathrm{ml} 0.9 \%$ saline $)$ were subcutaneously injected into the flanks of the mice. When the tumors reached $0.2-0.3 \mathrm{~cm}^{3}$, the mice were randomly assigned to one of three groups. For the treatment group, 50 or $100 \mathrm{mg} / \mathrm{kg} / \mathrm{day}$ S03-EA was administered daily for 15 days by intraperitoneal (i.p.) injection. The negative and positive control groups were treated with $0.9 \%$ saline and CTX, respectively, at a dose of $10 \mathrm{mg} / \mathrm{kg} /$ day every 3 days, according to the same schedule. On the last day, the mice in the treatment and control groups
( $n=10$ in each group) were anaesthetized with pentobarbital sodium intravenously, and sacrificed. The tumor volumes were recorded using Vernier calipers every two days and calculated by the following equation: $\mathrm{V}=\mathrm{ab}^{2} / 2$, where ' $\mathrm{a}$ ' represents the length and ' $b$ ' represents the width (21), and then transformed into relative values $(\mathrm{V})$ using the formula: $\mathrm{V}=\mathrm{V}_{\mathrm{t}} / \mathrm{V}_{0}$, where $\mathrm{V}_{0}$ is the initial tumor volume and $\mathrm{Vt}$ is the final tumor volume after sacrifice (22). The body and tumor weight of the mice were recorded following 15 days of treatment. All surgical procedures and care administered to the animals were in accordance with institutional guidelines of the of Second Hospital of Zhongnan University. The study was approved by the Committee on the Use of Live Animals in Teaching and Research of Capital Medical University (Beijing, China).

Observation of Bcl-2, Bax and VEGF expression in tumor cells treated with S03-EA. Two slices of the tumor tissue were selected randomly from each treatment group and the cells were observed in five fields. The expression rates of cells positive for Bcl-2, Bax and VEGF were calculated to obtain a conclusion. Paraffin sections were performed as previously described (23) and immunostained by the streptavidin-peroxidase conjugate method.

Statistical analysis. The results are expressed as the mean \pm standard deviation and are representative of at least three independent experiments. The individual comparisons were obtained by Duncan's multiple range test subsequent to the demonstration of homogeneity of variance with a one-way analysis of variance for more than two groups using SPSS version 13.0 (SPSS, Inc., Chicago, IL, USA). P $<0.001$ was considered to indicate a statistically significant difference between groups.

\section{Results}

SO3-EA inhibits the proliferation of SGC 7901 cells in vitro. The extracts of XKC-S03 inhibited the growth of the human gastric cancer cells. The growth inhibitory effects of four different extractions of XKC-S03 (S03-PE, EA, DM and BA) on the human gastric cancer SGC 7901 cell line were evaluated using MTT assays. The SGC-7901 cells were treated with four crude extractions of XKC-S03 at concentrations of 500, 250, 100,50 and $25 \mu \mathrm{g} / \mathrm{ml}$. The results demonstrated that treatment with PE, EA and DM extractions induced growth inhibition in the SGC-7901 cells, and that S03-EA had the greatest effect on cell viability (Fig. 1), with a half maximal inhibitory concentration $\left(\mathrm{IC}_{50}\right)$ of $25.89 \mu \mathrm{g} / \mathrm{ml}$. The dose-dependent cell proliferation column diagram indicates that S03-EA is an effective growth inhibitor of the gastric cancer SGC 7901 cell line in vitro (Fig. 1).

SO3-EA inhibits the proliferation of SGC 7901 cells in vivo. S03-EA showed dose-dependent suppression of SGC 7901 tumor growth compared with the negative saline control. At the end of the study (day 15), the established SGC 7901 xenograft mouse model (average tumor volume, $200 \mathrm{~mm}^{3}$ ) injected with i.p. S03-EA (50 or $100 \mathrm{mg} / \mathrm{kg} /$ day) demonstrated inhibition of tumor volume growth by 17.91 and $65.67 \%$, and of tumor weight growth by 25.70 and $64.79 \%$, respectively $(\mathrm{P}<0.001$ vs. $0.9 \%$ saline controls). By day 15 , the positive control, CTX, had reduced tumor volume and weight by 73.63 and $72.18 \%$, 
Table I. Tumor volume and weight of BALB/c nude mice treated with S03-EA and CTX.

\begin{tabular}{lcccccc}
\hline & \multicolumn{2}{c}{ Body weight, } & & & \\
\cline { 2 - 3 } Group & Pre-treatment & Post-treatment & & $\begin{array}{c}\text { Final tumor } \\
\text { volume, } \mathrm{cm}^{3}\end{array}$ & $\begin{array}{c}\text { Final tumor } \\
\text { weight, g }\end{array}$ & $\begin{array}{c}\text { Inhibition rate, \% } \\
\text { (volume/weight) }\end{array}$ \\
\hline Negative control & $21.85 \pm 0.99$ & $20.67 \pm 1.29$ & & $2.01 \pm 0.52$ & $2.84 \pm 0.39$ & \\
$\mathrm{CTX}$ & $21.46 \pm 0.63$ & $31.49 \pm 2.26$ & & $0.53 \pm 0.12$ & $0.9 \pm 0.28$ & $73.63 / 72.18^{\mathrm{a}}$ \\
$50 \mathrm{mg} / \mathrm{kg}$ & $21.37 \pm 1.11$ & $30.75 \pm 2.39$ & & $1.65 \pm 0.43$ & $2.11 \pm 0.61$ & $17.91 / 25.70^{\mathrm{b}}$ \\
$100 \mathrm{mg} / \mathrm{kg}$ & $20.11 \pm 0.68$ & $28.68 \pm 3.12$ & & $0.69 \pm 0.21$ & $1.00 \pm 0.38$ & $65.67 / 64.79^{\mathrm{a}}$ \\
\hline
\end{tabular}

${ }^{\mathrm{a}} \mathrm{P}<0.0001 ;{ }^{\mathrm{b}} \mathrm{P}<0.001$. S03-EA, ethyl acetate extract; CTX, cyclophosphamide.

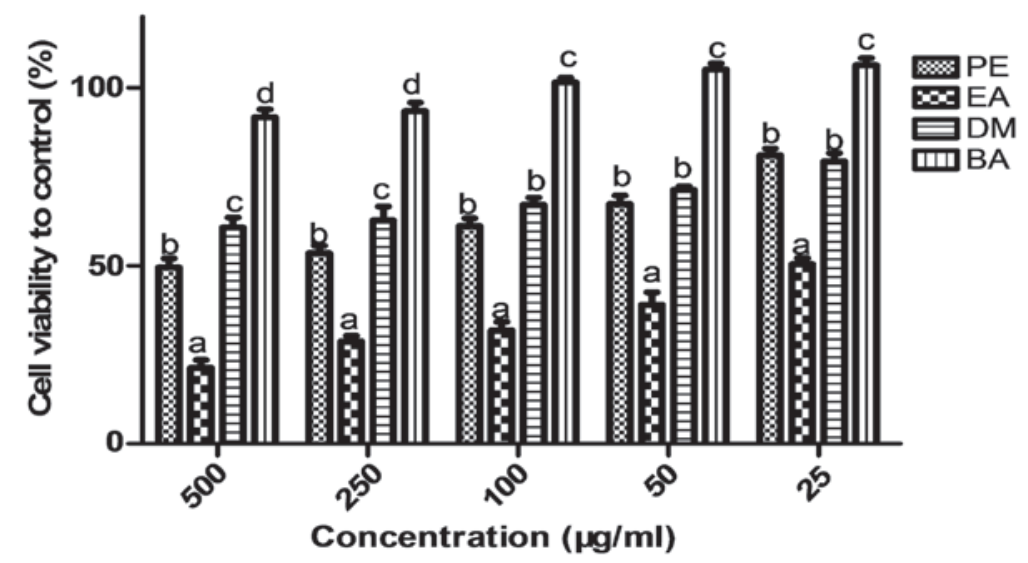

Figure 1. Four different extracts of XKC-S03 inhibit the proliferation of the SGC 7901 cell line. SGC 7901 cells were exposed to serial dilutions of S03-PE, -EA, -DM and -BA $(25-500 \mu \mathrm{g} / \mathrm{ml})$ for 24,48 or $72 \mathrm{~h}$ followed by analysis by MTT assay. Values not sharing a common superscript $\left({ }^{\mathrm{a}},{ }^{\mathrm{b}},{ }^{\mathrm{c}}\right.$ and $\left.{ }^{\mathrm{d}}\right)$ differ significantly (Duncan's multiple range test). Results are expressed as the mean \pm standard deviation ( $n=3), P<0.001$ denotes statistically significant differences. $P E$, petroleum ether; EA, ethyl acetate; DM, dichloride methane; BA, n-butyl alcohol.

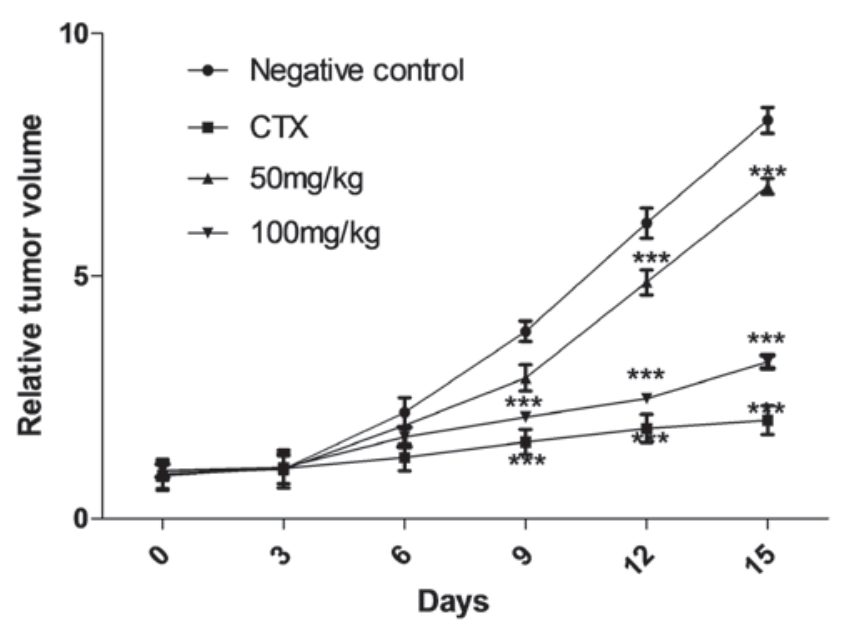

Figure 2. Relative SGC-7901-derived tumor volumes of the nude mice treated with 50 or $100 \mathrm{mg} / \mathrm{kg} \mathrm{S03-EA}$ or with the positive (CTX) or negative (saline) controls. Tumor volumes were measured and transformed to relative tumor volume as detailed in the Materials and methods section. Relative tumor volume is shown as the mean \pm standard deviation. ${ }^{* * *} \mathrm{P}<0.001$, denotes a significant difference compared with the negative control.

respectively. No significant difference was identified between this result and that obtained with $100 \mathrm{mg} / \mathrm{kg} \mathrm{S03-EA} \mathrm{(Table.} \mathrm{I).}$ Suppression of tumor growth was evident from the sixth day

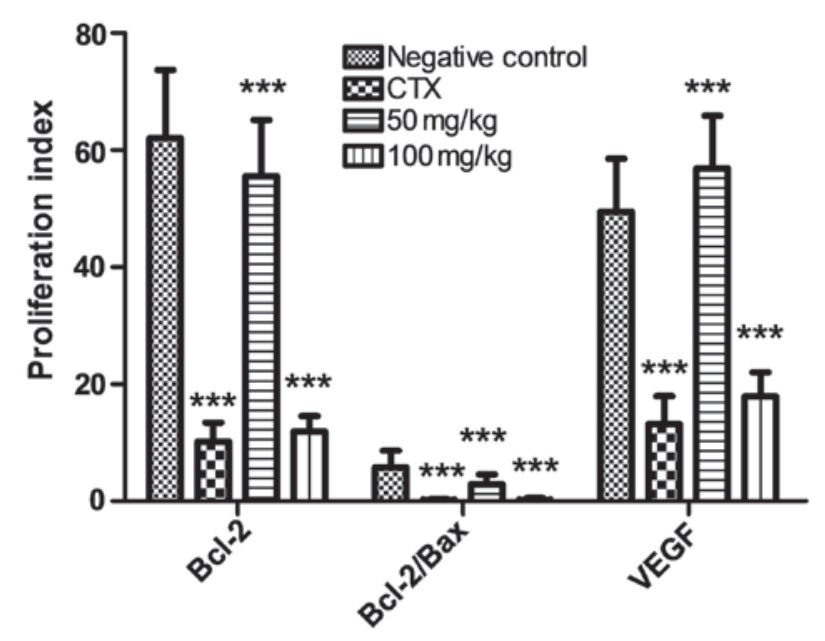

Figure 3. Proliferation index of the Bcl-2, Bax and VEGF proteins. Representative images of sections from each treatment group were stained with Bcl-2, Bax and VEGF antibodies, and counted to assess the proliferation. ${ }^{* * *} \mathrm{P}<0.001$, denotes a significant difference compared with the negative control. Bcl-2, B-cell lymphoma protein-2; Bax, Bcl-2-associated X protein; VEGF, vascular endothelial growth factor.

following treatment with S03-EA (Fig. 2), similar to the results observed in the CTX-treated group. In addition, no significant loss in body weight was identified in the S03-EA- and CTX-treated groups (Table I). The present in vivo study 
indicates that S03-EA is a potential therapeutic treatment of gastric cancer and is relatively non-toxic to nude mice.

S03-EA downregulates Bcl-2 and VEGF expression, and actives Bax expression in gastric cancer cells. The effect of S03-EA on the expression levels of Bcl-2, VEGF and Bax was investigated to examine the mechanism behind its inhibition of gastric cancer cell proliferation. As shown in Fig. 3, Bcl-2 and VEGF expression in the 100-mg S03-EA- and CTX-treated groups were suppressed in the gastric cancer cells. However, the expression of Bax was higher in these treatment groups, which correlates with the decrease in the $\mathrm{Bcl}-2 / \mathrm{Bax}$ ratio observed. This result of the present study is consistent with previous studies investigating other tumors (24).

\section{Discussion}

Prunella vulgaris $\mathrm{L}$. has been demonstrated to possess a variety of anticancer activities. In addition, there have been studies investigating its endophytic fungi as a potential source of novel drug development. Prunella vulgaris $\mathrm{L}$. was reported to be used in the treatment of gastric cancer as early as 1979 and revealed good curative effects (25). Subsequently, a Prunella vulgaris L. injection was developed by Shanghai Shuguang Hospital (Shanghai, China) and proved to be effective in the treatment of advanced gastric cancer and in SGC 7901 cells $(14,26)$. In view of these studies, the endophytic fungi from Prunella vulgaris $\mathrm{L}$ was investigated in the present study. Firstly, the activity of the endophytes isolated from the spicae of Prunella vulgaris L. against the SGC 7901 cell line was screened. The crude extract of the XKC-S03 fermentation broth demonstrated the most promising result. In the present study, it was identified that the S03-EA extract of XKC-S03 inhibited SGC 7901 cell proliferation in vitro and tumor growth in vivo.

The results of the present study indicated that S03-EA suppressed SGC 7901 cell growth in a dose- and time-dependent manner, with an $\mathrm{IC}_{50}$ value of $25.89 \mu \mathrm{g} / \mathrm{ml}$. A significant difference in inhibition activity was identified compared with the other three groups (S03-PE, -DM and -BA). According to the subsequent in vivo study, it was identified that the tumor volume and weight could be significantly reduced in mice following the sixth day of treatment with S03-EA. In addition, the average change in body weight subsequent to S03-EA treatment was not significant compared with that following CTX treatment (Table I). No gastrointestinal bleeding or other severe organ damage was identified in the S03-EA-treated mice, suggesting that it is safe for longer-term use. In order to explore the therapeutic mechanism of S03-EA-mediated inhibition, the expression of the three proteins, Bcl-2, Bax and VEGF, was analyzed in SGC 7901 cells.

The occurrence of tumors has a close association with apoptosis, a cellular event controlled by a balance between pro- and anti-apoptotic molecules, such as those belonging to the proto-oncogene Bcl-2 family. Among the Bcl-2 family, the $\mathrm{Bcl}-2$ protein and its associated protein $\mathrm{X}$ (Bax) are delegates. In contrast to $\mathrm{Bcl}-2$, Bax protein plays a pro-apoptotic role, activating apoptosis and initiating cell death $(27,28)$. The results of the present study demonstrated that S03-EA inhibited the proliferation of the SGC 7901 cells by upregulating
Bax expression and downregulating Bcl-2 expression. In addition, pro-angiogenic factors, such as VEGF, are also important to tumor cell proliferation, as they stimulate tumor progression, invasion and metastasis $(29,30)$. In the present study, the suppression of VEGF expression may therefore have reduced the proliferation of the gastric cancer cells.

In summary, the present study demonstrated that treatment with the S03-EA extract of XKC-S03 isolated from Prunella vulgaris $\mathrm{L}$. can suppress gastric cancer in mice. This finding lends support to existing studies on the therapeutic potential of active metabolites from Prunella vulgaris L., and the investigation of novel medicines for the treatment of gastric cancer.

\section{References}

1. Jemal A, Bray F, Center MM, Ferlay J, Ward E and Forman D: Global cancer statistics. CA Cancer J Clin 61: 69-90, 2011.

2. Li R, Wu X, Wei H and Tian S: Characterization of side population cells isolated from the gastric cancer cell line SGC-7901. Oncol Lett 5: 877-883, 2013.

3. Jackson C, Cunningham D and Oliveira J; ESMO Guidelines Working Group: Gastric cancer: ESMO clinical recommendations for diagnosis, treatment and follow-up. Ann Oncol 20 (Suppl 4): 34-36, 2009.

4. Verdecchia A, Mariotto A, Gatta G, Bustamante-Teixira MT and Ajiki W: Comparison of stomach cancer incidence and survival in four continents. Eur J Cancer 39: 1603-1609, 2003.

5. Liu CH, Zou XW, Lu H and Tan RX: Antifungal activity of Artemisia annua endophyte cultures against phytopathogenic fungi. J Biotechnol 88: 277-282, 2001.

6. Harikrishnan R, Kim JS, Kim MC, Balasundaram C and Heo MS: Prunella vulgaris enhances the non-specific immune response and disease resistance of Paralichthys olivaceus against Uronema marinum. Aquaculture 318: 61-66, 2011.

7. Skottová N, Kazdová L, Oliyarnyk O, Vecera R, Sobolová L and Ulrichová J: Phenolics-rich extracts from Silybum marianum and Prunella vulgaris reduce a high-sucrose diet induced oxidative stress in hereditary hypertriglyceridemic rats. Pharmacol Res 50: 123-130, 2004.

8. Cook NC and Samman S: Flavonoids - chemistry, metabolism, cardioprotective effects, and dietary sources. J Nutr Biochem 7: 66-76, 1996.

9. Lu J, Qin R and Ye S: Prunnela vulgaris L. extract improves cellular immunity in MDR-TB challenged rats. J Med Coll PLA 26: 230-237, 2011.

10. Zheng J, He J, Ji B, Li Y and Zhang X: Antihyperglycemic activity of Prunella vulgaris L. in streptozotocin-induced diabetic mice. Asia Pac J Clin Nutr 16 (Suppl 1): 427-431, 2007.

11. Zhang KJ, Zhang MZ, Wang QD and Liu WL: The experimental research about the effect of Prunella vulgaris L. on Raji cells growth and expression of apoptosis related protein. Zhong Yao Cai 29: 1207-1210, 2006 (In Chinese).

12. Collins NH, Lessey EC, DuSell CD, McDonnell DP, Fowler L, Palomino WA, Illera MJ, Yu X, Mo B, Houwing AM and Lessey BA: Characterization of antiestrogenic activity of the Chinese herb, prunella vulgaris, using in vitro and in vivo (Mouse Xenograft) models. Biol Reprod 80: 375-383, 2009.

13. Takahashi O, Okushiba S, Kondo S, Morikawa T, Hirano S, Miyamoto M, Shichinohe T, Hara T, Kawarada Y, Saito K and Takeuchi M: Esophageal pemphigus vulgaris with carcinoma: postoperative steroid therapy based on pemphigus-related antibodies. Dis Esophagus 18: 413-417, 2005.

14. Zhao AG, Li T, You SF, et al: Effects of Wei Chang An on expression of multiple genes in human gastric cancer onto nude mice. World J Gastroenterol 14: 693-700, 2008.

15. Liang HQ, Xing YM, Chen J, Zhang D, Guo S and Wang C: Antimicrobial activities of endophytic fungi isolated from Ophiopogon japonicus (Liliaceae). BMC Complement Altern Med 12: 238, 2012.

16. Santiago C, Sun L, Munro MH and Santhanam J: Polyketide and benzopyran compounds of an endophytic fungus isolated from Cinnamomum mollissimum: biological activity and structure. Asian Pac J Trop Biomed 4: 627-632, 2014. 
17. Kim S, Shin DS, Lee T and Oh KB: Periconicins, two new fusicoccane diterpenes produced by an endophytic fungus Periconia sp. with antibacterial activity. J Nat Prod 67: 448-450, 2004.

18. Vaz AB, Mota RC, Bomfim MR, Vierira ML, Zani CL, Rosa CA and Rosa LH: Antimicrobial activity of endophytic fungi associated with Orchidaceae in Brazil. Can J Microbiol 55: 1381-1391, 2009.

19. Rasul A, Khan M, Yu B, Ma T and Yang H: Xanthoxyletin, a coumarin induces $\mathrm{S}$ phase arrest and apoptosis in human gastric adenocarcinoma SGC-7901 cells. Asian Pac J Cancer Prev 12: 1219-1223, 2011.

20. Yu J, Guo QL, You QD, Zhao L, Gu HY, Yang Y, Zhang HW, Tan Z and Wang X: Gambogic acid-induced G2/M phase cell-cycle arrest via disturbing CDK7-mediated phosphorylation of CDC2/p34 in human gastric carcinoma BGC-823 cells. Carcinogenesis 28 : 632-638, 2007

21. Xian XS, Park H, Cho YK, Lee IS, Kim SW, Choi MG, Chung IS, Han KH and Park JM: Effect of a synthetic cannabinoid agonist on the proliferation and invasion of gastric cancer cells. J Cell Biochem 110: 321-332, 2010.

22. Chua CW, Lee DT, Ling MT, Zhou C, Man K, Ho J, Chan FL, Wang X and Wong YC: FTY720, a fungus metabolite, inhibits in vivo growth of androgen independent prostate cancer. Int J Cancer 117: 1039-1048, 2005.

23. Shin IS, Jeon WY, Shin HK, Cha SW and Lee MY: Banhabaekchulchunma-tang, a traditional herbal formula attenuates absolute ethanol-induced gastric injury by enhancing the antioxidant status. BMC Complement Altern Med 13: 170, 2013.

24. Singh NP and Lai H: Selective toxicity of dihydroartemisinin and holotransferrin toward human breast cancer cells. Life Sci 70: 49-56, 2001.
25. Lin W, Zheng L, Zhuang Q, et al: Spica prunellae promotes cancer cell apoptosis inhibits cell proliferation and tumor angiogenesis in a mouse model of colorectal cancer via suppression of stat 3 pathway. BMC Complement Altern Med 13: $144,2013$.

26. Zhang JF, Zhang JG, Kuai XL, Zhang H, Jiang W, Ding WF, Li ZL, Zhu HJ and Mao ZB: Reactivation of the homeotic tumor suppressor gene CDX2 by 5-aza-2'-deoxycytidine-induced demethylation inhibits cell proliferation and induces caspase-independent apoptosis in gastric cancer cells. Exp Ther Med 5: 735-741, 2013.

27. Yi B, Liu D, He M, Li Q, Liu T and Shao J: Roles of the ROS/AMPK signaling pathway in tetramethylpyrazine-induced apoptosis in gastric cancer cells. Oncol Lett 6: 583-589, 2013.

28. Yang B, Johnson TS, Thomas GL, Watson PF, Wagner B, Furness PN and EI Nahas AM: A shift in the Bax/Bcl-2 balance may activate caspase- 3 and modulate apoptosis in experimental glomerulonephritis. Kidney Int 62: 1301-1313, 2002.

29. Wang X, Li L, Wang B and Xiang J: Effects of ursolic acid on the proliferation and apoptosis of human ovarian cancer cells. J Huazhong Univ Sci Technolog Med Sci 29: 761-764, 2009.

30. Hung KC, Hsieh PM, Yang KL, Lin KJ, Chen YS and Hung $\mathrm{CH}$ : Effect of thalidomide on the expression of vascular endothelial growth factor in a rat model of liver regeneration. Oncol Lett 5: 852-856, 2013. 